DOI: http://doi.org/10.4038/ss.v49i1.4714

\title{
Sri Lanka's Total Factor Productivity Change during Conflict and Post-Conflict Periods
}

\author{
Tharindi Gunaratna Nugawela ${ }^{1}$
}

\begin{abstract}
This study analyses Sri Lanka's Total Factor Productivity (TFP) change during conflict and post-conflict periods to assess whether there has been any improvement during the post-conflict period using Solow's Residual Method (SRM)) and an index number approach (Hicks-Moorsteen Total Factor Productivity Index - HMTFPI). Findings of both approaches reveal that the TFP growth during the conflict period was higher than that of the post-conflict period. Based on the decomposition of HMTFPI into Technological Change (TC) and Efficiency Change (EC) indices, it was revealed that the main source of TFP change throughout the sample period is TC. EC had been negative throughout the sample period.
\end{abstract}

Key Words: Total factor productivity, efficiency change, technological change, Sri Lanka

JEL Classification: D24; O39; O40

1 The author is currently on postgraduate study leave. Corresponding email: i.gunaratna@monash.edu, tharindi@cbsl.lk. The author wishes to thank Dr. Rasika Yatigammana and the anonymous reviewers for their comments and advice. The views presented in this paper are those of the author and do not necessarily indicate the views of the Central Bank of Sri Lanka. 


\section{Introduction}

Productivity growth is an important aspect of economic and social development of a country. Productivity growth improves competitiveness, and is hence a required ingredient to attract foreign investments and also to boost export trade. Productivity drives the economic growth and helps realise improved living standards. Productivity is a measure of performance commonly defined as the ratio of outputs to inputs (measured in terms of volumes). Larger values of this measure are more desirable, since it is associated with better performance. Productivity is a relative concept, and it could be compared with the productivity measured during another year, or with the productivity of a different unit (firm or an economy), at the same point of time. Total Factor Productivity (TFP) is referred to as the productivity measure involving all factors of production (Coelli et al., 2005). Unlike labour productivity (or capital productivity), which considers only the labour input (or capital input), TFP is a comprehensive measure of productivity.

This paper aims to analyse the change in Sri Lanka's TFP during the conflict and post-conflict periods to assess whether there have been any improvements during the post-conflict period. In order to measure the change in TFP, two commonly used techniques in literature are used in this paper. Firstly, a production function approach involving the Cobb-Douglass type of production function (Solow's Residual Method (SRM)) is used. Secondly, an index number approach (Hicks-Moorsteen Total Factor Productivity Index) is used. These methods are the applicable tools in analysing productivity trends in an overall economy, in the absence of price data on factors of production (Coelli et al., 2005).

The next section provides a review of the theoretical framework of productivity analyses, a review of literature on productivity during conflict periods and productivity trends in Sri Lanka. Section 3 outlines the methodology. Explanations on data, variables and data sources are provided in section 4 . Sections 5 and 6 present the analysis and conclusions.

\section{Literature review}

\subsection{Theoretical framework}

This study is aimed at analysing productivity trends at the aggregate economy level (as opposed to the firm level). This section reviews productivity analysis tools, focusing mainly on the aggregate economy.

Calculation of productivity as the ratio of outputs to inputs is trivial when it involves a single input and output. However, in reality there are multiple inputs and outputs which lead to the need of aggregating the inputs into a single measure before constructing productivity measures. This gives rise to the concept of TFP. The production frontier is an important concept when computing measurements of productivity that involve multiple inputs and 
outputs. The production frontier represents the maximum attainable output at each level of inputs. It is the representation of the current state of technology. Firms can operate either on the frontier (efficient) or beneath the frontier (inefficient) (Coelli et al., 2005). The CobbDouglas form of the production function is a simple and popular form used in productivity analyses. Translog and Constant Elasticity of Substitution are some examples of other functional forms used in productivity estimation (Coelli et al., 2005).

The change in productivity of an economy consists of two mutually exclusive and exhaustive components: Technological Change (TC) and Efficiency Change (EC). TC refers to a shift in the production frontier, and EC refers to movements towards or away from the production frontier (Coelli et al., 2005). Therefore, efficiency characterises the difference between observed output and some ideal or potential output that can be generated with existing resources, at a given point of time. It is the static aspect of productivity change. TC, on the other hand characterises the dynamic aspect of productivity change, indicating improvements in production technology from one time period to another, or a shifting of the production possibility frontier.

There are four main categories of productivity analysis techniques discussed in the literature, namely: Growth Accounting techniques, Index Number techniques, Frontier Analyses approaches and State Space Modelling. The first two approaches are the tools of analysing trends in productivity, whereas the other two approaches are the tools of analysing factors affecting productivity change in its components, TC and EC. Applicability of these approaches depends on the type of the analysis, for example, time series, cross-sectional or panel data. Further, these methods can also be grouped as parametric or non-parametric approaches. These techniques are not stand-alone techniques.

\subsection{Trends in TFP growth during conflict periods}

Literature on TFP growth during conflict periods reveal mixed results. Field (2008) has found that based on private non-farm data, post-Second World War TFP in the United States has increased at a slower rate than during the war and pre-war periods. A study by Smolny (2000) reveals that there has been a rapid productivity growth in European countries and Japan during the early post-war period of 1947-1950 on average. Nevertheless, there have been significant differences in the speed of productivity growth among the industrialised countries of the sample. There has been a rapid economic and productivity growth in West Germany after the Second Wald War (Eichengreen and Ritschl , 2009), due to fast convergence to the potential output resulting from the structural changes introduced and the rigorous regulations imposed. Comin and Hobjin (2001) studied the post and pre-second world war growth trajectories of a sample of countries. It was revealed that the war effect moved up to a higher growth path than they were on, before the war. This boost in growth was mainly driven by growth in TFP, which was accompanied by the increases in technology. The postwar European history analysis by Stone (2008) discusses the TFP growth differences between the 
Western and the Eastern European countries and the Soviet Union. He argues that the TFP growth acceleration in the Western Europe was due to the high level of technological adoption, whereas the slow TFP growth in the Eastern Europe and the Soviet Union was due to low incentives for innovation at the firm level even though investment expenditure incurred was high. Studies on TFP change during conflict periods focus mainly on the growth in TFP itself. Literature on extensive analysis of sources of TFP change during conflict periods is rare to find.

Literature on Sri Lanka's TFP change are mainly focused towards analyzing the trends in specific industries. For example, Thayaparan and Pratheepan (2014) study the change in TFP in the banking industry. Dutz and O'Connell(2013) analyse the impact of key business environment indicators on productivity, innovation, and growth in Sri Lanka using data of the 2004 and 2011 World Bank Enterprise Surveys. Duma (2007) analyses the sources of economic growth using the growth accounting framework, which however, does not cover the post-conflict period. This study is focused on analysing and comparing the trends in TFP during the conflict and post-conflict periods in Sri Lanka, as little or no effort has been directed towards analysing post-conflict TFP trends.

The objective of this study is to analyse whether there has been any improvement in TFP growth during the post-conflict period, compared to the conflict period in Sri Lanka and what sources of productivity were prominent during the conflict and post-conflict periods.

During a conflict period, the process of efficient allocation of resources and also the innovation process are disturbed, leading to a decline in productivity. Based on the findings of Comin and Hobjin (2001), the first hypothesis is formed:

H1: There has been an improvement in TFP growth in Sri Lanka during the post-conflict period, compared to the conflict period.

Commonly, developing countries, or countries with resource barriers improve productivity mainly through efficient allocation of existing resources. In developing economies, where technological progress takes more time, the prominent source of productivity change could be efficiency change (Headey et al., 2010). It is hypothesised that during the conflict period, the main source of TFP change was efficiency change, and during the post-conflict period, the main source of TFP change was technological progress.

$\mathrm{H} 2$ : The main source of TFP change during the conflict period was efficiency change and the main source of TFP change during the post-conflict period was technological progress. 


\section{Methodology}

\subsection{Solow's residual}

The pioneering idea of the growth accounting method of productivity measurement comes from Solow's work, popularly known as the Solow Residual (Solow, 1957). Solow's famous article shed light on measuring technological change with respect to the production function of an economy. The central idea of the Solow Residual is based on a standard Neo Classical production function of output $\left(Y_{t}=A_{t} f\left(K_{t}, L_{t}\right)\right)$ and decomposition of the growth in output at time t, $\left(\frac{\Delta Y_{t}}{Y_{t-1}}\right)$ in to the weighted average of the growth of the two inputs Capital and Labour (the weights are considered as relative shares of Capital and Labour), and the growth in Total Factor Productivity (TFP). Hence, the decomposition of a Neo-Classical production function, with Cobb-Douglas form $\left(Y_{t}=A_{t} K_{t}^{\alpha} L_{t}^{1-\alpha}\right)$ can be expressed as:

$$
\frac{\Delta Y_{t}}{Y_{t-1}}=\alpha \frac{\Delta K_{t}}{K_{t-1}}+(1-\alpha) \frac{\Delta L_{t}}{L_{t-1}}+\frac{\Delta A_{t}}{A_{t-1}}
$$

Where $K_{t}$ and $L_{t}$ denote capital and labour available at time period t, $\alpha$ is the output share of capital and $\frac{\Delta A_{t}}{A_{t-1}}$ is considered as the growth in TFP at time t.

Equation (1) can be re-written as:

$$
\text { Growth in TFP }=\frac{\Delta Y_{t}}{Y_{t-1}}-\alpha \frac{\Delta K_{t}}{K_{t-1}}-(1-\alpha) \frac{\Delta L_{t}}{L_{t-1}}
$$

The main assumptions of Solow's method are (Oecd, 2001):

- The production technology can be represented by a production function relating gross output to inputs, which exhibits constant returns to scale.

- Productivity changes are Hicks-neutral, where, for a given capital to labour ratio, the ratio of marginal product of capital to marginal product of labour remains unchanged.

- $\quad$ Factor input markets are competitive.

The assumption of constant returns to scale implies that the only source of productivity change is due to TC. This gives rise to an issue of measuring productivity change in developing economies. In such countries TC is a long run phenomenon and the prominent source of productivity change could be EC (Headey, Alauddin, \& Prasada Raob, 2010). 


\subsection{Index number approaches}

\subsubsection{Input and output distance functions}

Index number approaches of productivity measurements are commonly based on the concept of distance functions (Coelli, Prasada Rao, O'Donnell, \& Battese, 2005). Distance functions were first introduced by Malmquist (1953) and gained attention in efficiency and productivity analysis with the introduction of the Malmquist index number approach by Caves et al. (1982). The idea of an input (or output) distance function is, measuring the radial contractions (or expansions) of a production point at which the firm operates with respect to the point on the production frontier (or the isoquant). It allows describing technology while measuring efficiency and productivity, without the need of defining an objective such as cost minimisation or profit maximisation. Input distance functions are given as the minimal proportional contraction of the inputs given the outputs, for a given production technology. Output distance functions are given by the maximal proportion expansion of outputs given inputs and the production technology (Coelli et al., 2005).

The distance function is defined for the production possibility set $\Omega$ at time t,

$$
\text { where, } \Omega=\{(x, y) \mid x \text { can produce } y\}
$$

and $\mathrm{x}$ is an input vector and $\mathrm{y}$ is an output vector.

The distance function is defined by rescaling the length of an output (output distance function) or an input (input distance function) vector, using the production possibility function as a reference.

$$
D_{O}^{t}(x, y)=\min \left\{\delta \mid\left(\frac{y}{\delta}\right) \in \Omega\right\}
$$

$D_{O}^{t}(x, y)$ is non-decreasing and convex in y and non-increasing, linearly homogeneous and quasi-convex in x. If $D_{O}^{t}(x, y)>1, \mathrm{y}$ is not producible by x. If $D_{O}^{t}(x, y) \leq 1, D_{O}^{t}(x, y)$ measures the (in)efficiency. If $D_{O}^{t}(x, y)=1$, it indicates full efficiency, where more outputs cannot be produced without increasing the inputs (Coelli et al., 2005). Figure 1 illustrates the concept of the distance function. 
Figure 1: Output oriented distance function

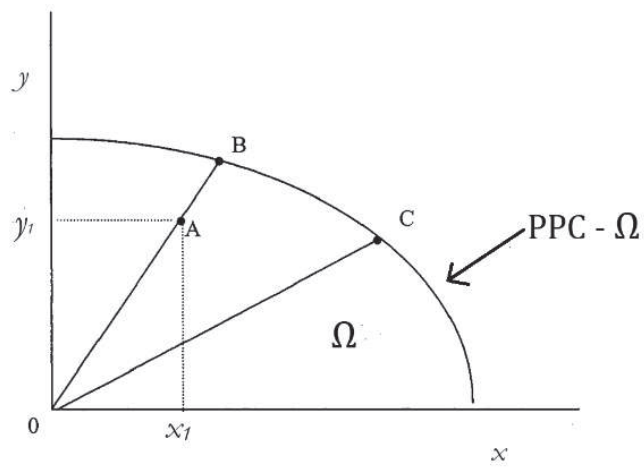

Source: Coelli et al. (2005)

Here the economy uses input $\mathrm{x}$ and produces output $\mathrm{y}$. The production possibility set $\Omega$ is the area bounded by the production possibility frontier, PPC- $\Omega$ and $\mathrm{x}$ and $\mathrm{y}$ axes. If the firm is using input level $x_{1}$ to produce $y_{1}$, defined by the point $\mathrm{A}$, the value of the distance function $D_{O}^{t}\left(x_{1}, y_{1}\right)$ is equal to the ratio $\delta=0 \mathrm{~A} / \mathrm{OB}$ (Coelli et al., 2005).

\subsubsection{Malmquist index and its variants}

The Malmquist index number approach (Caves, Christensen, \& Diewert, 1982), became more popular in recent literature, due to its flexibility. Caves et al. re-introduced the index number method first introduced by (Malmquist, 1953), which involves computations with the use of input or output distance functions. Unlike the Solow residual, which is restricted to constant returns to scale, the Malmquist productivity index has the flexibility of variable returns to scale production technologies. Due to its flexibility, the Malmquist index is widely used in firm level and industry level studies. Färe, Grosskopf, Norris, and Zhang (1994), Taskin and Zaim (1997) and Maudos, Pastor, and Serrano (1999) apply the Malmquist index in country level studies.

The Malmquist productivity index for two observed input-output vectors $\left(\mathrm{x}_{\mathrm{t}}, \mathrm{y}_{\mathrm{t}}\right)$ and $\left(\mathrm{x}_{\mathrm{t}+1}\right.$, $\left.y_{t+1}\right)$ at time points, $t$ and $t+1$, can be defined with the use of output distance functions (alternatively, with input distance functions) as in equation (4) (Coelli et al., 2005). The maximum proportional expansion is measured by the output distance function (alternatively the minimal proportional contraction measured by the input distance function) which is evaluated at state of prevailing technology. 


$$
M_{o}\left(y_{t+1}, y_{t}, x_{t+1}, x_{t}\right)=\left(\frac{D_{0}^{t}\left(y_{t+1}, x_{t}\right)}{D_{0}^{t}\left(y_{t}, x_{t}\right)} \times \frac{D_{0}^{t+1}\left(y_{t+1}, x_{t+1}\right)}{D_{0}^{t+1}\left(y_{t+1}, x_{t}\right)}\right)^{1 / 2}
$$

Where $D_{0}^{s}\left(q_{t}, x_{t}\right)$ is the output distance from observation of period t, computed using technology of period $\mathrm{s}$ as the reference technology.

If the index value is greater than 1 , it indicates an improvement in TFP, while a value less than 1 , indicates deterioration in TFP.

\subsubsection{Hicks-Moorsteen index}

Although the Malmquist index appears to be very popular, it suffers from a number of theorotical deficiencies (O’Donnell (2010), Kerstens and Van de Woestyne (2014) and Peyrache (2013)). The Malmquist index fails to decompose TFP into its sources, as it does not satisfy axioms of index number theory, which allow such decomposition. Indices that are suitable for such decompositions should be multiplicatively complete.

To overcome this deficiency in the Malmquist index, Hicks-Moorsteen Total Factor Productivity Index (HMTFPI) is used. It can be defined as the ratio of growth in outputs to growth in inputs (Diewert, 1992), where growth in outputs and inputs are measured through index numbers.

$$
\text { HMTFPI }=\frac{\text { Growth in Outputs }}{\text { Growth in Inputs }}
$$

Bjurek (1996) re-introduced a modified approach of calculating the existing Hicks-Moorsteen Total Factor Productivity Index (HMTFPI) as a ratio of Malmquist output and input indices.

$$
\text { HMTFPI }=\frac{\text { Malmquist Output Index }}{\text { Malmquist Input Index }}
$$

Once growth in inputs and outputs are measured through an appropriate index (among any available indices), measuring change in productivity through HMTFPI is easy, and it also provides the source of change (whether it is technological change or efficiency change) (Nemoto and Goto, 2008). Accordingly, the decomposition of HMTFPI in to TC and EC component indices can be presented as:

$$
\text { HMTFPI }=\frac{M_{o}\left(y_{t}, y_{t+1}, x_{t}, x_{t}\right)}{M_{I}\left(y_{t}, y_{t+1}, x_{t}, x_{t}\right)}=\left(\frac{D_{0}^{t}\left(y_{t+1}, x_{t+1}\right)}{D_{0}^{t+1}\left(y_{t+1}, x_{t+1}\right)} \times \frac{D_{0}^{t}\left(y_{t}, x_{t}\right)}{D_{0}^{t+1}\left(y_{t}, y_{t}\right)}\right)^{\frac{1}{2}} \times\left(\frac{D_{0}^{t+1}\left(y_{t+1}, x_{t+1}\right)}{D_{0}^{t}\left(y_{t}, x_{t}\right)}\right)
$$




$$
\begin{aligned}
& \text { where, } T C=\left(\frac{D_{0}^{t}\left(y_{t+1}, x_{t+1}\right)}{D_{0}^{t+1}\left(y_{t+1}, x_{t+1}\right)} \times \frac{D_{0}^{t}\left(y_{t}, x_{t}\right)}{D_{0}^{t+1}\left(y_{t}, y_{t}\right)}\right)^{1 / 2} \text { and } \\
& E C=\left(\frac{D_{0}^{t+1}\left(y_{t+1}, x_{t+1}\right)}{D_{0}^{t}\left(y_{t}, x_{t}\right)}\right)
\end{aligned}
$$

A value of a component index greater than 1 indicates improvement, while a value less than 1 indicates deterioration of the conditions.

Further, in the absence of panel data, the HMTFPI is preferred over the Malmquist index, as the Malmquist approach uses the concept of cone technology, which requires a dataset large enough to provide a good description of the underlying technology (Coelli et al., 2005)).

In this study, DPIN (Decomposition of Productivity Index Numbers) software (O'Donnell, 2011) has been used to compute the HMTFPI and its components.

\section{Data}

The real Gross Domestic Product (GDP) series with the base year as 2002, published by the Department of Census and Statistics (DCS) was used, as it contains data covering both the conflict and post-conflict periods. The GDP $(2010=100)$ series covers only the post-conflict period. Annual data starting 2002 to 2014 was used for the analysis. Quarterly data could not be used due to inconsistencies in the frequency of available employment data (data for some quarters during the sample period are not available) and the unavailability of a quarterly series of gross capital formation.

The total number of hours worked (Total number employed $\times$ Average number of hours worked per person) was used as the labour input. The average number of hours worked per person is taken from the Penn World Tables (PWT) Version 9.0 (Feenstra et al.,2015). The official statistics series of Sri Lankan Labour Force published by the DCS has a few inconsistencies regarding the coverage of data during several years, due to the inability of conducting the Labour Force Survey in areas where the conflict was happening. In order to correct the discrepancy, a correction on the number employed variable of the DCS series was applied using growth in the employment variable of PWT database as the growth rates of the DCS series and the PWT series move closely for the years that DCS data are complete. Therefore, the growth rate of the PWT series for the years 2002 to 2011 is applied to reestimate the employment data series for the period from 2002 to 2011 (see Appendix A.1 for details).

In order to estimate the capital stock, the Perpetual Inventory Method (PIM) employing 6\% depreciation (Iyer et al., 2008) was used employing gross capital formation data series for Sri Lanka, which is available in the World Bank Database (Appendix A.2). 
The output's share of labour ( $[\alpha-1]$ of the Cobb-Douglas production function) is taken as the long-run average (2000-2015) of the labour share of output variable of the PWT database (Appendix A.3).

When determining the sample period for the study, data limitations had to be considered. The GDP series $(2002=100)$ covers the period from 2002 to 2015 . The labour force data series of DCS does not cover the entire island for the period from 1990-2010 (Appendix AII). The conflict began in the early 1980s and ended in 2009. Based on data availability, this study analyses the TFP change during the period from 2003-2009 (conflict period) and from 20102015 (post-conflict period).

\section{Analysis}

\subsection{The change in total factor productivity based on Growth Accounting Framework}

SRM analysis of TFP change reveals that the average conflict period TFP growth $(3.24 \%)$ is greater than the post-conflict period TFP growth $(1.98 \%)$ in Sri Lanka. The highest TFP growth of $5.96 \%$ during the sample period is recorded for the year 2008, when the conflict was at its highest level, before the war ended in 2009. The lowest TFP growth for the sample period is recorded for the year 2013, which is a TFP regress of $-0.74 \%$. Since SRM TFP change accounts only for the Technological Change (TC) aspect of TFP change, findings reveal that irrespective of the conflict situation during the conflict period, a higher level of positive TC has happened. The TFP growth dynamics can be further explained by a more disaggregated level TFP analysis of TFP components, EC and TC, through the index number approach.

Figure 2: Change in TFP during 2003-2015 period based on the Solow's residual

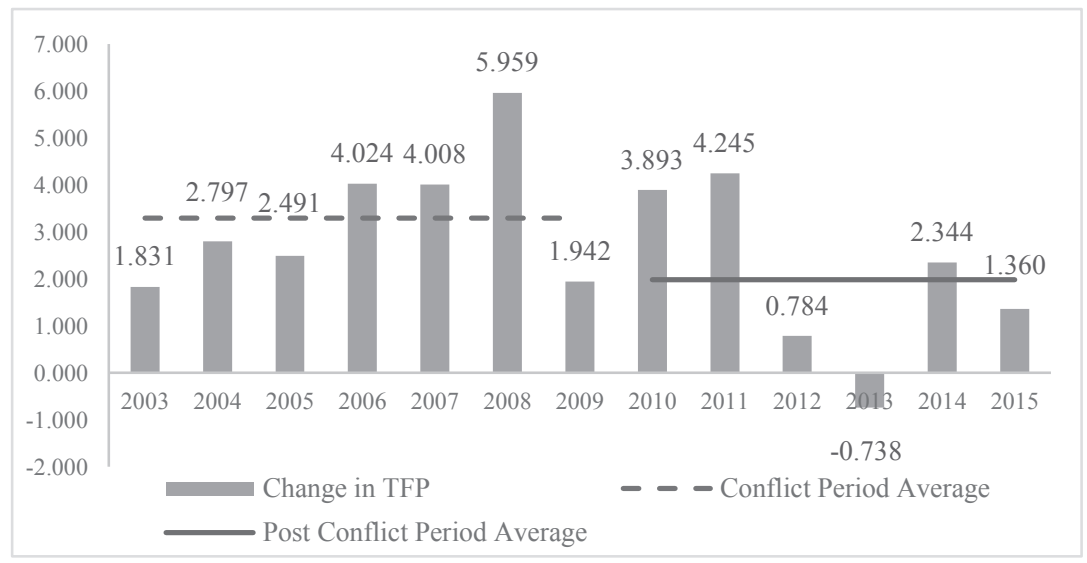

Source: Author's calculations 


\subsection{TFP change based on the index number approach}

Overall TFP change as per the HMTFPI values also indicate that the average TFP growth during the conflict period is greater than the post-conflict period TFP growth. The average TFP index during the conflict period is 1.0242, while the same during the post-conflict period is 1.0159 .

Throughout the period, TC has been positive, except for the year 2012. Average TC during the conflict period (1.043) is greater than that during the post-conflict period (1.034), which is consistent with the SRM findings.

The TFP change during the sample period is entirely due to positive TC, as the EC has been negative or neutral for the entire period. The negative EC has pushed the overall TFP growth down. Furthermore, the EC decline during the post-conflict period (average index value is 0.983 ) is minutely higher than the same during the conflict period (average index value is $0.982)$.

The highest TFP change is observed during the year 2008 (consistent with the SRM findings). The lowest TFP change (negative change) is observed in 2012 (inconsistent with SRM findings).

Figure 3: Change in TFP during 2003-2015 period based on the HMTFPI

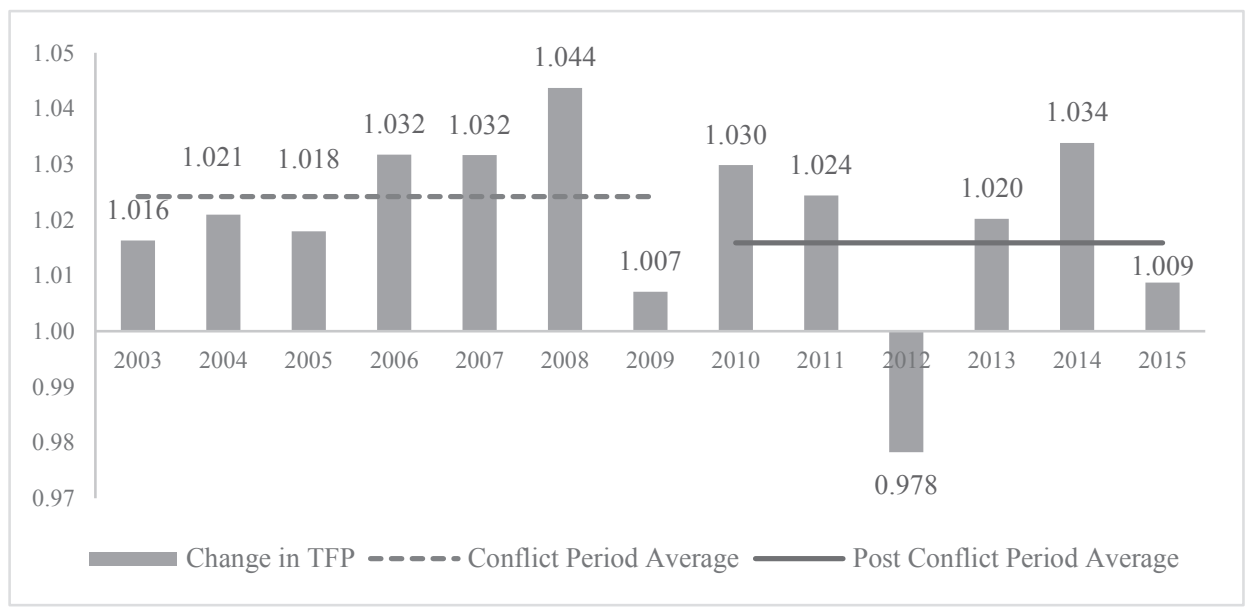

Source: Author's calculations 
Figure 4: Technological Change during 2003-2015 Period based on the HMTFPI

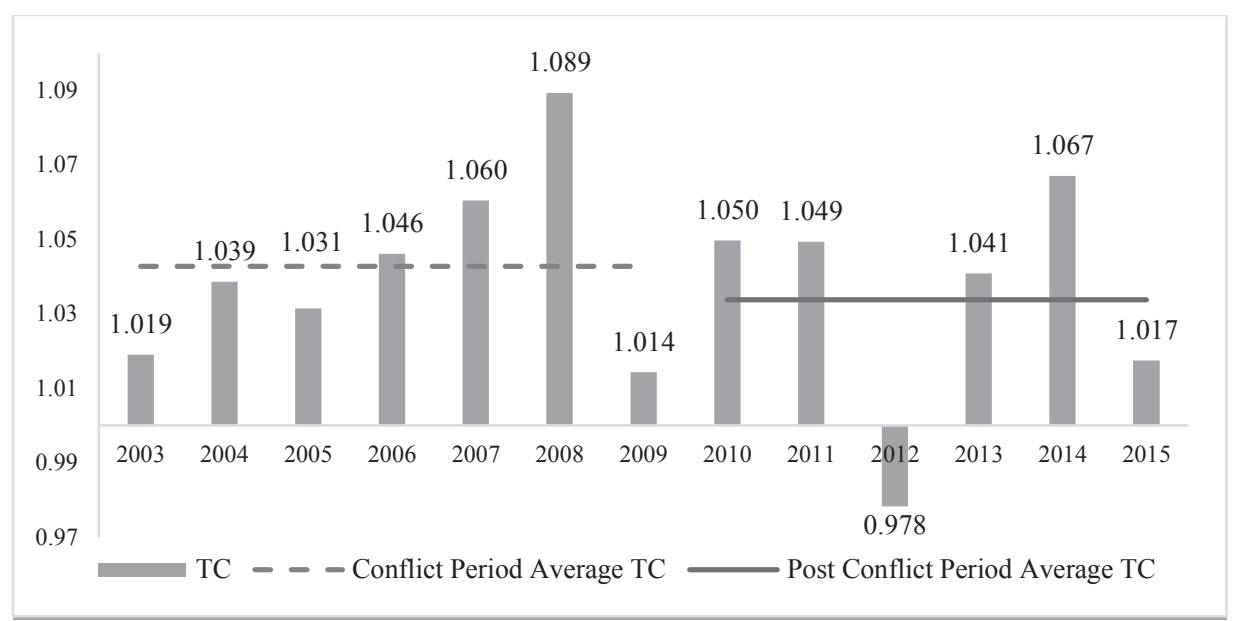

Source: Author's calculations

Figure 5: Efficiency Change during 2003-2015 Period based on the HMTFPI

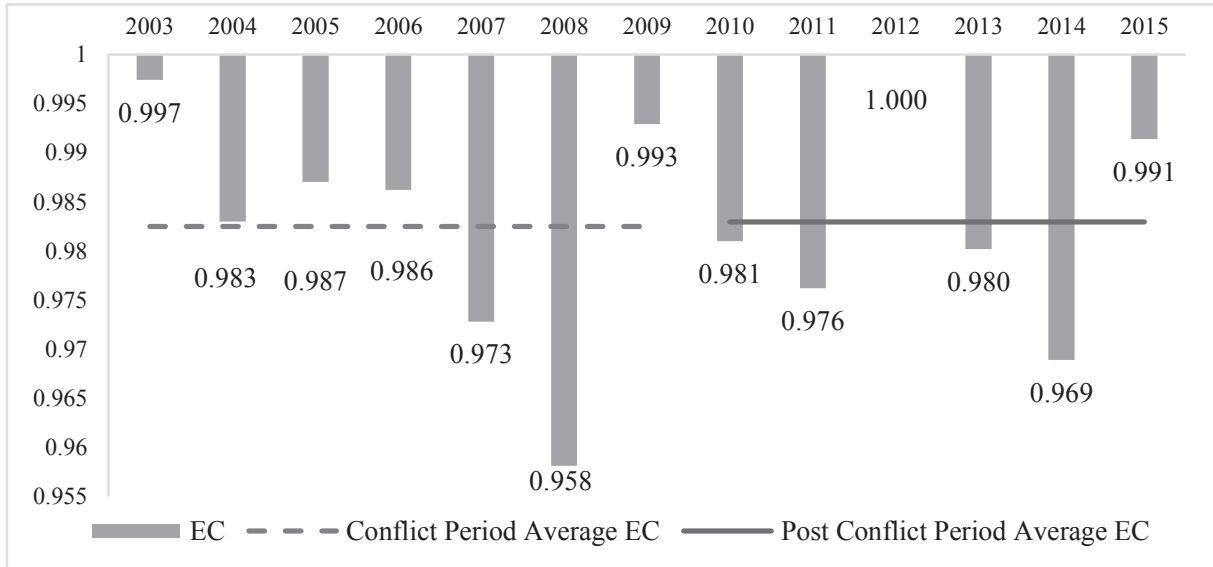

Source: Author's calculations

Overall TFP change as per the HMTFPI values also indicate that the average TFP growth during the conflict period is greater than the post-conflict period TFP growth. The average TFP index during the conflict period is 1.0242 , while the same during the post-conflict period is 1.0159 . 
Throughout the period, TC has been positive, except for the year 2012. Average TC during the conflict period (1.043) is greater than that during the post-conflict period (1.034), which is consistent with the SRM findings.

The TFP change during the sample period is entirely due to positive TC, as the EC has been negative or neutral for the entire period. The negative EC has pushed the overall TFP growth down. Furthermore, the EC decline during the post-conflict period (average index value is 0.983 ) is minutely higher than that during the conflict period (average index value is 0.982 ).

The highest TFP change is observed during the year 2008 (consistent with the SRM findings). The lowest TFP change (negative change) is observed for 2012 (inconsistent with SRM findings).

Table 1: Average TFP. TC and EC during conflict and post-conflict periods

\begin{tabular}{|c|c|c|}
\hline \multirow{2}{*}{ Method } & \multicolumn{2}{|c|}{ Average Change } \\
\hline & Conflict Period & Post-Conflict Period \\
\hline \multicolumn{3}{|l|}{ Solow's Residual } \\
\hline TFP Change & 3.293 & 1.981 \\
\hline \multicolumn{3}{|l|}{ HMTFPI } \\
\hline Technological Change & 1.043 & 1.034 \\
\hline Efficiency Change & 0.982 & 0.983 \\
\hline TFP Change & 1.0242 & 1.0159 \\
\hline
\end{tabular}

\section{Conclusions}

This study was carried out to investigate TFP growth trends in the Sri Lankan economy with respect to the conflict and post-conflict periods. The analysis was carried out with two approaches, the SRM and the HMTFPI.

Assuming that during a conflict period, the process of efficient allocation of resources and also the innovation process are disturbed, leading to a decline in productivity, the first hypothesis was formed. The first hypothesis (H1) stated that there has been an improvement in TFP during the post-conflict period, compared to the conflict period. Based on the findings of both approaches, $\mathrm{H} 1$ was rejected where it was revealed that the TFP growth during the conflict period was higher than that during the post-conflict period.

The second hypothesis was formulated with the aim of understanding what sources of productivity were prominent during the conflict and post-conflict periods. It was hypothesized that the main source of TFP change during the conflict period was efficiency change and the main source of TFP 
change during the post-conflict period was the technological progress (H2). H2 cannot be assessed through SRM as it assumes the TFP change of the economy was solely due to TC. Based on the HMTFPI, H2 was rejected, as it revealed that the main source of TFP change throughout the sample period is TC, and EC had been negative throughout the sample period.

Positive EC is imperative for a developing country, particularly, if the growth momentum is expected to be bolstered through foreign investments. Negative EC deters investors. Attention should be drawn towards increase in efficiency though effective resource allocation and minimizing wasteful inputs.

Even though TC is the sole contributor towards TFP growth in the economy during the sample period, post-conflict TC has decelerated compared to that of the conflict period average, which could be due to the increased focus on low yielding infrastructure development projects and new investment projects started in the post-conflict period. Out of the total nominal gross domestic capital formation (investment), 38.4\% was used for government infrastructure development projects during the post-conflict period, while that during the conflict period was $22.3 \%$ (Central Bank of Sri Lanka, 2015, 2014 and 2011). Stone (2008) argues that high a level of investment spending on infrastructure development alone is inadequate for post-conflict TFP to grow. Firm level efforts on improving technology and efficiency are also required. However, to support such firm level efforts, institutional continuity and the absence of radical changes in policy are required (Eichengreen and Ritschl, 2009).

Both approaches revealed that there has been a rapid TFP growth during the early postconflict period (in 2010 and 2011). This is consistent with the findings of Smolny (2000) and Eichengreen \& Ritschl (2009), where countries experienced rapid TFP growth during the early post-Second World War period.

The increase in the labour input during the conflict period was $1.13 \%$ compared to a $2.27 \%$ increase during the post-conflict period. The growth in real capital formation (growth in real gross domestic capital formation) during the conflict period was $9 \%$, while that for the postconflict period is $10 \%$. Meanwhile, the average economic growth during the conflict period was $5.9 \%$, while that during the post-conflict period was $6.4 \%$.

Irrespective of the higher level of increase in both the inputs and the outputs during the postconflict period, the TC during the conflict period has been higher. In spite of the higher level of inputs generating higher level of outputs during the post-conflict period, the economy during the conflict period has enjoyed higher TFP growth with relatively low negative EC (relatively low inefficiency) and relatively high positive TC. This implies that the quality of capital and labour inputs used during the conflict period could have been higher than that of the post-conflict period. Quality of labour force comes through the knowledge, skill, experience and expertise level of individuals. Quality of capital inputs can be sourced through the use of high-tech equipment, and innovation through research and development. 


\section{References}

Bjurek, Hans. "The Malmquist total factor productivity index." The Scandinavian Journal of Economics (1996): 303-313.

Caves, Douglas W., Laurits R. Christensen, and W. Erwin Diewert. "The economic theory of index numbers and the measurement of input, output, and productivity." Econometrica: Journal of the Econometric Society (1982): 1393-1414.

Central Bank of Sri Lanka. Central Bank of Sri Lanka Annual Report 2015. Central Bank of Sri Lanka, Colombo, 2016.

Coelli, Timothy J., et al. An introduction to efficiency and productivity analysis. Springer Science \& Business Media, 2005.

Comin, Diego, and Bart Hobijn. "Technology diffusion and postwar growth." NBER macroeconomics annual 25.1 (2011): 209-246.

Diewert, W. Erwin. "Fisher ideal output, input, and productivity indexes revisited." Journal of Productivity Analysis 3.3 (1992): 211-248.

Duma, Nombulelo. Sri Lanka's sources of growth. No. 7-225. International Monetary Fund, 2007.

Dutz, Mark A., and Stephen D. O'Connell. Productivity, innovation and growth in Sri Lanka: An empirical investigation. The World Bank, 2013.

Eichengreen, Barry, and Albrecht Ritschl. "Understanding West German economic growth in the 1950s." Cliometrica 3.3 (2009): 191-219.

Färe, Rolf, et al. "Productivity growth, technical progress, and efficiency change in industrialized countries." The American economic review (1994): 66-83.

Field, Alexander J. "The impact of the Second World War on US productivity growth 1." The Economic History Review 61.3 (2008): 672-694.

Feenstra, Robert C., Robert Inklaar, and Marcel P. Timmer. "The next generation of the Penn World Table." American economic review 105.10 (2015): 3150-82.

Headey, Derek, Mohammad Alauddin, and DS Prasada Rao. "Explaining agricultural productivity growth: an international perspective." Agricultural Economics 41.1 (2010): $1-14$.

Iyer, Krishna G., Alicia N. Rambaldi, and Kam Ki Tang. "Efficiency externalities of trade and alternative forms of foreign investment in OECD countries." Journal of Applied Econometrics 23.6 (2008): 749-766. 
Kerstens, Kristiaan, and Ignace Van de Woestyne. "Comparing Malmquist and HicksMoorsteen productivity indices: Exploring the impact of unbalanced vs. balanced panel data." European Journal of Operational Research 233.3 (2014): 749-758.

Maudos, Joaquín, José Manuel Pastor, and Lorenzo Serrano. "Total factor productivity measurement and human capital in OECD countries." Economics letters 63.1 (1999): $39-44$.

Malmquist, Sten. "Index numbers and indifference surfaces." Trabajos de estadística 4.2 (1953): 209-242.

Nemoto, Jiro, and Mika Goto. "Productivity, efficiency, scale economies and technical change: A new decomposition analysis of TFP applied to the Japanese prefectures." Journal of the Japanese and International Economies 19.4 (2005): 617-634.

OECD Publishing. Measuring productivity-OECD Manual: Measurement of Aggregate and IndustryLevel Productivity Growth. Organisation for Economic Co-operation and Development, 2001.

O'Donnell, Christopher J. DPIN version 1.0: a program for decomposing productivity index numbers. No. WP012010. School of Economics, University of Queensland, Australia, 2010.

Peyrache, Antonio. "Hicks-Moorsteen versus Malmquist: a connection by means of a radial productivity index." Journal of Productivity Analysis 41.3 (2014): 435-442.

Smolny, Werner. "Post-War Growth, Productivity Convergence and Reconstruction." Oxford Bulletin of Economics and Statistics 62.5 (2000): 589-606.

Solow, Robert M. "Technical change and the aggregate production function." The review of Economics and Statistics (1957): 312-320.

Stone, Dan, ed. The Oxford Handbook of Postwar European History. Oxford University Press, 2012.

Taskin, Fatma, and Osman Zaim. "Catching-up and innovation in high-and low-income countries." Economics letters 54.1 (1997): 93-100.

Thayaparan, A., and Tharmalingam Pratheepan. "Evaluating total factor productivity growth of commercial banks in Sri Lanka: An application of Malmquist index." Journal of Management Research, ISSN (1941).

World Bank. " Gross Capital Formation (Constant 2010 US\$).” World Development Indicators. The World Bank Group, 2015, data.worldbank.org/indicator/NE.GDI.TOTL.CD. Accessed 20 Jul. 2016. 


\section{Appendices}

\section{A.1 Correcting the discrepancies in the employment data series}

Sri Lanka's labour force data series published by the Department of Census and Statistics (DCS) contains a few discrepancies due to the inadequate coverage caused by the problems of conducting the Labour Force Survey during the conflict period in conflict affected areas. As such, data from 2002 to 2011 does not cover the entire island.

\section{Table A1: Coverage of the Quarterly Labour Force Survey (QLFS) of the DCS} (1990-2015)

\begin{tabular}{cl}
\hline \hline Period & \multicolumn{1}{c}{ Coverage } \\
$1990-2002$ & Data excluding both Northern and Eastern provinces. \\
2003 & Data excluding the Northern Province. \\
2004 & Data excluding both Mullaitivu and Killinochchi districts \\
2005 & Data covers the entire island. QLFS was conducted as a one-off survey in August 2005. \\
$2006-2007$ & Data excluding both Northern and Eastern provinces. \\
$2008-2010$ & Data excluding the Northern Province. \\
$2011-2015$ & Data covers the entire island. \\
\hline
\end{tabular}

Source: DCS

In order to correct the discrepancy, a correction on the number employed variable of the DCS series was done using growth in the employment variable of PW'T database. The growth rates of the DCS series and the PWT series move closely for the years that data are complete. Therefore, the growth rate of the PWT series for the years 2002 to 2011 is applied to reestimate the employment data series for the period from 2002 to 2011.

\section{Figure A1: Growth in employment}

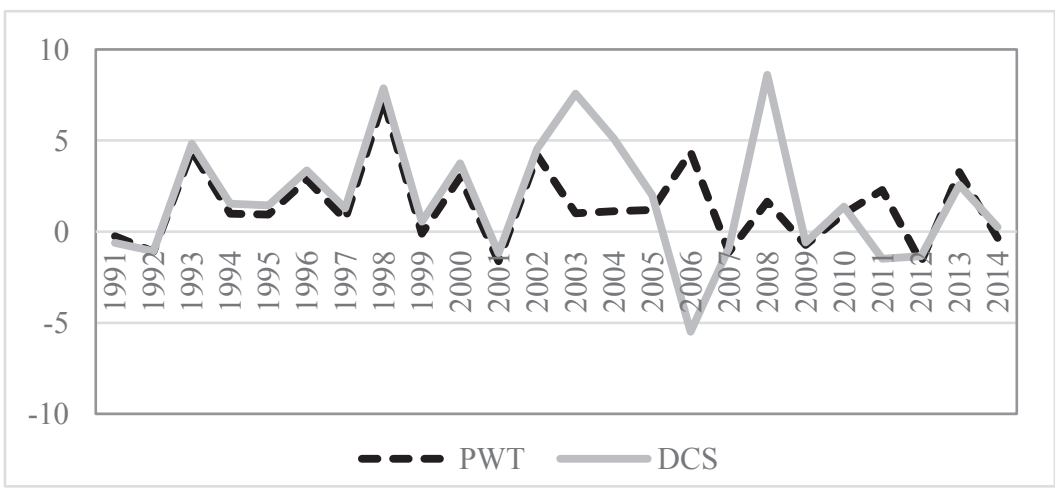

Sources: PWTDCS and author's calculations 
Table A2: Re-constructed employment data series

\begin{tabular}{cccc}
\hline \hline Year & $\begin{array}{c}\text { DCS Number } \\
\text { Employed Series }\end{array}$ & $\begin{array}{c}\text { Growth in the Number } \\
\text { Employed as per PWT }\end{array}$ & $\begin{array}{c}\text { Re constructed } \\
\text { Series }\end{array}$ \\
2001 & 6,236 & 4.180 & 6,496 \\
2002 & 6,519 & 1.017 & 6,562 \\
2003 & 7,013 & 1.114 & 6,635 \\
2004 & 7,394 & 1.188 & 6,714 \\
2005 & 7,518 & 4.372 & 7,008 \\
2006 & 7,105 & -1.131 & 6,928 \\
2007 & 7,042 & 1.645 & 7,042 \\
2008 & 7,648 & -0.721 & 6,992 \\
2009 & 7,602 & 0.974 & 7,060 \\
2010 & 7,707 & 2.297 & 7,222 \\
2011 & 7,592 & & 7,489 \\
2012 & 7,489 & & 7,681 \\
2013 & 7,681 & & 7,700 \\
2014 & 7,700 & & 7,831 \\
2015 & 7,831 & & \\
\hline
\end{tabular}

Sources: PWT, DCS and author's calculations

Note: Highlighted numbers are calculated based on PWT growth rates

\section{A.2 Perpetual inventory method of estimating capital stock}

The method used to estimate the capital stock is the Perpetual Inventory Method (PIM). Following Iyer et al. (2008), the following equation was used to estimate annual capital stock for each country using gross domestic capital formation data.

$$
K_{t}=(1-d) K_{t-1}+I_{t}
$$

Where $\mathrm{K}$ is the capital stock, $\mathrm{I}$ is the investment (Gross capital formation), and $\mathrm{d}$ is the depreciation rate, which is assumed to be $6 \%$ following Iyer et al. (2008). The initial capital stocks were estimated based on the assumption that capital and output grow at the same rate. The initial capital stock was calculated for the year 1970 with;

$$
K_{1970}=\frac{I_{1970}}{(g+d)}
$$

Where $\mathrm{g}$ is the average growth rate of output calculated for the period between 1961 and 1970. 


\section{A.3 Obtaining the long run average of the labour share of output using the Penn World} Tables labour share of output series for Sri Lanka

As per the PW'T series of Labour Share of Output (LSO), there are three main eras. The first period is from 1961-1987, where LSO remained almost constant around 0.79. The second period is from 1988-1999, where LSO declined drastically. The third period is from 20002015, where LSO oscillated around 0.69. The long run LSO for the sample period is considered as 0.69 , which is $(1-\alpha)$ for the analysis.

Figure A2: Labour share of output

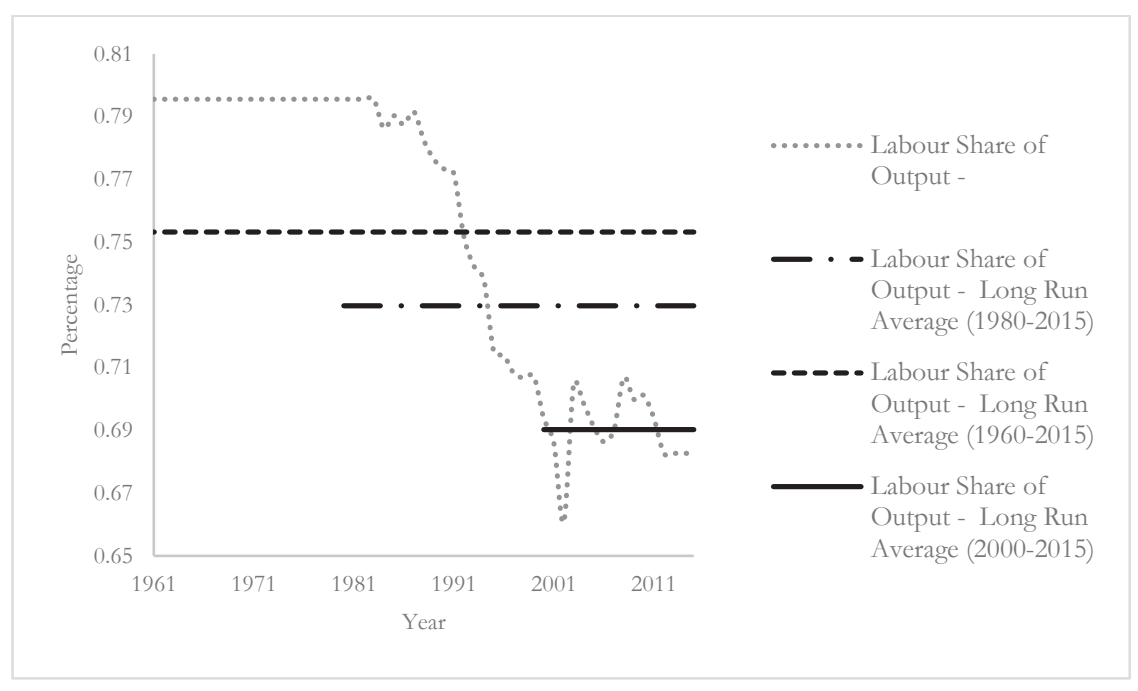

Sources: PW'T and author's calculations 